\title{
Potential significance of epstein barr virus-positive mucosa in patients with nasopharyngeal carcinoma
}

\author{
Saleh AlDhahri ${ }^{* 1}$, Raneem Alshareef ${ }^{1}$, Hanadi Fatani ${ }^{2}$ and Aziz A. Chentouf ${ }^{3}$ \\ ${ }^{1}$ Otolaryngology Head and Neck Unit; King Fahad Medical City, King Saud University P.O. Box 59046, Riyadh, KSA \\ ${ }^{2}$ Pathology and Clinical Laboratory Medicine, Anatomic Pathology Department, King Fahad Medical City, P.O. Box 59046, Riyadh, KSA \\ ${ }^{3}$ Pathology and Clinical Laboratory Medicine, Immunology Department, King Fahad Medical City, P.O. Box 59046, Riyadh, KSA
}

\begin{abstract}
Introduction: Nasopharyngeal carcinoma (NPC) is one of the most Virus-associated malignancies. In Saudi Arabia, it represent about one-third of head and neck mucosal malignancies. Early detection and treatment of nasopharyngeal carcinoma are the key factor in the disease outcome. The objective of this study was to determine the possibility of detecting latent Epstein-Barr virus infection in histologically normal mucosa of patients with nasopharyngeal carcinoma and its potential clinical implications in predicting disease's recurrence or persistence.

Materials and methods: All patients diagnosed with nasopharyngeal carcinoma from 2006 to 2012 at King Fahad Medical City (KFMC) clinics were retrospectively reviewed for EBV-mRNA expression in both healthy and malignant tissues using insitu Hybridization assay. The correlation between Epstein-Barr virus detection and variables of our cohort were evaluated.

Results: Sixty-one patients were enrolled in the study. The majorities of patients were male (80.3\%), aged 40-60 years (60.6\%) and were classified with WHO type III NPC (85\%). While $98.4 \%$ of specimens with malignant cells had positive Epstein-Barr virus-in situ hybridization, only $6.6 \%$ were also positive for latent EBV infection in normal mucosal cells. All normal epithelium cells that were positive for EBV have positive Epstein-Barr virus-in situ hybridization in tumors. Only one case had Epstein-Barr virus-in situ hybridization negative in both normal and malignant cells.

Conclusion: The detection of EBV in nasopharyngeal mucosa in the absence of a tumor can be strong indication for carcinoma and could be used in the detection of early and recurrent disease.
\end{abstract}

\section{Introduction}

Nasopharyngeal Carcinoma (NPC) is a highly malignant tumor [1] that is considered the most common primary neoplastic tumor of the nasopharynx [2]. Clinically, NPC is characterized by local invasion and early distant metastasis [3]. NPC tumor-genesis is linked to multiple factors including environmental, behavioral, genetic alterations and infectious (Epstein-Barr Virus) factors [4]. NPC is rare in most parts of the world, with an incidence of $<1$ per 100,000 annually [5], In Saudi Arabia, it ranks the first (35\%) among all head and neck cancers and 17th $(2.9 \%)$ amongall cancers, with male predominance $(2: 1)$ with crude incidence for male 2.1/100,000 annualy. [6], [7].

Patients with NPC most commonly present with a neck mass, and then to a lesser extent with nasal symptoms such as nasal obstruction, chronic sinusitis, or epistaxis [8]. With the progression of disease otological complaints such as tinnitus, hearing loss or fluid in the middle ear become evident [8]. The presence of neurological symptoms such as headache or cranial nerves palsy usually indicates advanced local disease with skull base or intracranial extension [8]. Although the diagnosis of NPC can readily be made, it can be challenging in most patients due to non-specific symptoms and/or inadequately diagnostic materials $[9,10]$. Treatment of NPC includes combined radiochemotherapy or radiotherapy alone that usually induces complete remission, especially in the early stages of the disease. Despite this high rate of initial local control [11], it may be difficult to diagnose persistent or recurrent disease postradiotherapy and postchemoradiotherapy, because of necrosis and treatment effect, especially when the recurring tumor is small tissue in the nasopharynx, skull base or a small lymph node in the neck.

The detection of clonal EBV genome in precancerous lesions indicates that EBV latent infection is an early event in the tumorigenesis of NPC [12]. Other studies have shown the value of increasing EBV viral genome plasma load as an indicator of recurrent tumor [13]. Many techniques have been used to detect EBV latent infection, but in situ hybridization for EBV-encoded

RNA (EBER-ISH or EBV-ISH) is considered the gold standard [14] and the most sensitive and practical method for detecting EBV [15]. The presence of EBV-encoded RNA in benign mucosa has not been thoroughly investigated. This study attempted to compare EBV detection by using in-situ hybridization (ISH) in both normal and malignant mucosa of patients with confirmed primary nasopharyngeal carcinoma [16].

Correspondence to: Dr. Saleh AlDhahri, Otolaryngology Head and Neck Unit; King Fahad Medical City Medical City, King Saud University, P.O. Box 59046, Riyadh; KSA, Tel: +9664786100 ext:1419 \& 1420; E-mail: saldhahri@ksu.edu.sa

Key words: nasopharynx, carcinoma, EBV, hybridization, mucosa

Received: July 17, 2016; Accepted: August 19, 2016; Published: August 22, 2016 


\section{Materials and methods}

\section{Cohort characteristics}

All patients diagnosed with NPC and having archived materials from 2006 to 2012 were considered for this study. Patients who received any chemotherapy or radiotherapy to the head and neck regions before nasopharyngeal biopsies and those who did not have available pathological blocks were excluded from the study. The EBV genome expressions were scored using ISH in both normal and malignant cells of the nasopharynx. Pretreatment assessment including complete history and physical examination with endoscopy, and routine blood tests and imaging information were extracted from patients' medical records. Disease staging and radiological findings and follow-up were collected from patients' medical records. A senior head and neck pathologist reviewed all pathology slides.

\section{In Situ hybridization technique}

ISH were performed for EBV in formalin fixed paraffin-embedded tissue (FFPET); ISH for mRNA negative and positive probes was also performed. Samples were fixed in $10 \%$ neutral formalin and two sections of 5- $\mu \mathrm{m}$ thickness were made. One was stained with haematoxylin and eosin for histopathological examination. The tumors were classified based on World Health Organization nasopharyngeal classification.

The other section was used for ISH. ISH was performed with EBV peptide nucleic acid (PNA) probe/fluorescein (Dako, Denmark) and detected using a PNA ISH detection kit. Hybridization lasted $1.5 \mathrm{~h}$ at $55^{\circ} \mathrm{C}$ and was visualized by alkaline phosphatase (AP)-conjugated antifluorescein antibodies. Nitro blue tetrazolium (NBT)/bromochloro indoyl phosphate (Dako, Denmark) was used as a substrate for AP. To test the sensitivity and specificity of ISH, both negative and positive controls supplied by the manufacturer were used. A case was considered positive if the nucleus of a tumor cell stained dark blue or black.

\section{Results}

Of the 119 patients treated at the Otorhinolaryngology Head and Neck Surgery Clinics in KFMC between 2006 and 2012, only 61 patients were eligible for this study. The remaining cases were excluded because of the lack of pathology archived materials and/or prior treatment. Table 1 shows the study cohort characteristics. The majority of patients $(60.6 \%)$ were in the age range of $40-60$ year with a median age of 50 years. The male: female ratio of patients was $4: 1$ (80.3\%:19.7\%). Fiftyfive patients (85.2\%) had advanced disease (stage III), 7 type II (11.5\%), and only 2 type I WHO subtypes.

Table 1. Characteristics of patients at presentation with nasopharyngeal carcinoma.

\begin{tabular}{|l|c|c|}
\hline \multicolumn{2}{|c|}{ Characteristics } & No. \\
\hline Age (median=50 years) & 2 & $\%$ \\
\hline$(\leq 20)$ & 10 & 3.3 \\
\hline$(20-40)$ & 37 & 16.4 \\
\hline$(40-60)$ & 12 & 60.6 \\
\hline$(\geq 60)$ & & 19.7 \\
\hline Gender & 49 & 80.3 \\
\hline Male & 12 & 19.7 \\
\hline Female & & \\
\hline WHO type & 2 & 3.3 \\
\hline I & 7 & 11.5 \\
\hline II & 52 & 85.2 \\
\hline III & & \\
\hline
\end{tabular}

WHO=World Health Organization
Table 2. EBV-ISH Results

\begin{tabular}{|l|c|c|}
\hline EBV-ISH Status & Normal epithelium & Cancerous epithelium \\
\hline Positive (\%) & $4(6.6 \%)$ & $60(98.4 \%)$ \\
\hline Negative (\%) & $57(93.4 \%)$ & $1(1.6 \%)$ \\
\hline
\end{tabular}

A)

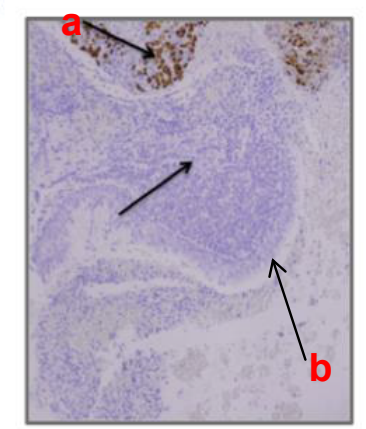

B)

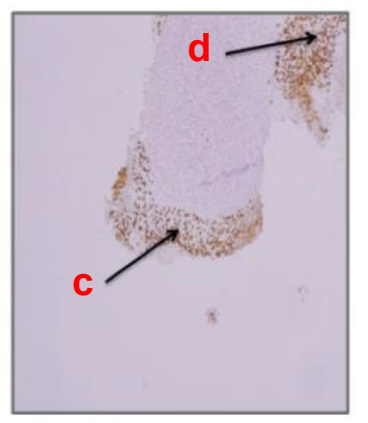

Figure 1. (A) A represesntative slide from a patient with EBV-positive infection in malignant tissue and no EBV infection the in normal tissue and (B) a representative slide from a patient with EBV -positive infection in both malignant and benign tissues.

a. EBV POSITIVE in malignant cells

b. EBV negative in normal epithelium

c. EBV positive in normal epithelium

d. EBV positive in malignant cells

In situ hybridization assays showed that among the 61 specimens analyzed, the majority $(n=56)$ were EBV positive tumors and negative normal mucosa. Table 2, summarizes the results of EBV-ISH of these patients. In four of the remaining 5 patients, both the tumors and histologically normal mucosa were positive for EBV. In addition, one patient was negative for EBV-ISH for both malignant and benign tissues. Figure $1 \mathrm{~A}$ and $\mathrm{B}$ show EBV-ISH staining of NPC biopsy showing staining differences between normal and malignant tissues.

All four patients with positive EBV in the tumor and matching normal mucosa were male above the age of 40 years. Three had type III WHO and one had type II nasopharyngeal carcinoma. One of them presented with metastasis to the lung and spine and received palliative chemotherapy only; his last follow up was in 2013 and the patient died few months later from his disease. The other three patients received neoadjuvant chemotherapy followed by concurrent chemoradiotherapy, of which two are still being followed up and one is currently lost to follow-up. The details of their follow up are summarized in Table 3.

\section{Discussion}

NPC is a common and serious disease in Saudi Arabia, as it accounts for about $30-40 \%$ of all head and neck cancers. With variation and development of different modalities for the detection of EBV in NPC, ISH is a unique method because it can confirm the existence of the EBV genome in the nuclei of malignant cells, regardless of infected lymphocytes in the peripheral blood.

The presence of a viral genome in the normal nasopharyngeal epithelium in a subset of the cohort of this study is a novel finding, and positive EBV results in the absence of tumor cells may suggest recurrent disease in a previously treated patient and thus require the performance of additional biopsies. A histologically normal looking mucosa may require EBV testing and if it is positive, then the possibility of a malignant tumor may be high and a repeat biopsy is 
Table 3. Follow-up and treatment of patients with positive EBV in the normal mucosa.

\begin{tabular}{|c|c|c|c|c|}
\hline Patient & TNM staging & Last $\mathbf{F} / \mathbf{U}$ & Status & Treatment modality \\
\hline 35 y old male & T4N2M1 & December/ 2013 & $\begin{array}{l}\text { Died with the disease at } 26 \\
\text { months post diagnosis }\end{array}$ & $\begin{array}{l}\text { Cisplatin based neoadjuvant followed by Concurrent } \\
\text { chemoradiation }\end{array}$ \\
\hline 24 y old male & T3N1M0 & July /2012(lost F/U) & $\begin{array}{l}\text { Free of disease at last } \mathrm{F} / \mathrm{U} \text { at } \\
27 \text { months post treatment }\end{array}$ & $\begin{array}{l}\text { Cisplatin based neoadjuvant followed by Concurrent } \\
\text { chemoradiation }\end{array}$ \\
\hline 39 y old male & $\mathrm{T} 2 \mathrm{~N} 2 \mathrm{M} 0$ & December $/ 2014$ & $\begin{array}{l}\text { Free of disease } 48 \text { month post } \\
\text { treatment }\end{array}$ & $\begin{array}{l}\text { Cisplatin based neoadjuvant followed by concurrent } \\
\text { chemoradiation }\end{array}$ \\
\hline 52 y old male & T3N1M0 & February/2015 & $\begin{array}{l}\text { Free of disease } 26 \text { months } \\
\text { post treatment }\end{array}$ & Cisplatin-based concurrent chemoradiation \\
\hline
\end{tabular}

recommended. The incidence of this cancer was higher in male than female in our series and this is not surprising, as this has been shown in a previous study in the Saudi Arabia (5). The demographics of our series are similar to other series by different groups in Saudi Arabia and South Asia (15). We showed that all EBV-positive benign cells were found in patients with invasive carcinoma and it may be beneficial to confirm the diagnosis of recurrent NPC even in the absence of invasive carcinoma in the provided specimen. This benefit may be seen in situations where the diagnosis is confusing because of the presence of many reactive infiltrate or after radiochemotherapy, as the presence of atypical cells may not be enough to diagnose recurrent/persistent disease. Although our sample size was limited and most of our patients had type II and III nasopharyngeal carcinoma; future studies with a sufficient number of patients may support our findings.

Our results may be limited because we excluded patients without paraffin block specimens; despite this, the majority of the WHO type carcinoma in our patients was WHO type III. However, there was no significant difference in EBV-ISH positivity in relation to histological types.

\section{Conclusion}

EBV is found at a high frequency among Saudi patients with nasopharyngeal carcinoma, which supports its role in the pathogenesis of the tumor. EBV-ISH in benign nasopharyngeal epithelium may be found in small number of patients and this finding may has a potential to be useful as a histologic tumor marker for diagnosis and screening for post-treatment recurrence. However more studies with larger number of patients (including treatment failure) are needed to come up with a firm conclusion in this regards.

\section{References}

1. Shao Y, Jiang H, Wu X, Luo Y, Tang W (2014) p16 promoter hypermethylation is associated with increased risk of nasopharyngeal carcinoma. Mol Clin Oncol 2: 11211124. [Crossref]

2. Thompson L (2006) World Health Organization classification of tumours: pathology and genetics of head and neck tumours. Ear Nose Throat J 85: 74. [Crossref]
3. Ou H, Li Y, Kang M (2014) Activation of miR-21 by STAT3 induces proliferation and suppresses apoptosis in nasopharyngeal carcinoma by targeting PTEN gene. PLoS One 9: e109929. [Crossref]

4. Lung ML, Cheung AK, Ko JM, Lung HL, Cheng Y, Dai W (2014) The interplay of host genetic factors and Epstein-Barr virus in the development of nasopharyngeal carcinoma. Chin J Cancer 33: 556-568. [Crossref]

5. Sarmiento MP1, Mejia MB (2014) Preliminary assessment of nasopharyngeal carcinoma incidence in the Philippines: a second look at published data from four centers. Chin J Cancer 33: 159-164. [Crossref]

6. Al-Rajhi N, El-Sebaie M, Khafaga Y, AlZahrani A, Mohamed G, et al. (2009) Nasopharyngeal carcinoma in Saudi Arabia: clinical presentation and diagnostic delay. East Mediterr Health J 15: 1301-1307. [Crossref]

7. Al-Eid HS, Arteh SO (2010) Cancer incidence report: Saudi Arabia 1999-2000. Riyadh, Saudi Arabia, National Cancer Registry Authority.

8. Yap YY, Hassan S, Chan M, Choo PK, Ravichandran M (2007) Epstein-Barr virus DNA detection in the diagnosis of nasopharyngeal carcinoma. Otolaryngol Head Neck Surg 136: 986-991. [Crossref]

9. Gao Y, Liu JJ, Zhu SY, Yi X (2014) The diagnostic accuracy of ultrasonography versus endoscopy for primary nasopharyngeal carcinoma. PLoS One 9: e99679. [Crossref]

10. Tabuchi K, Nakayama M, Nishimura B, Hayashi K, Hara A (2011) Early detection of nasopharyngeal carcinoma. Int J Otolaryngol 2011: 638058. [Crossref]

11. Yoshizaki T, Ito M, Murono S, Wakisaka N, Kondo S, et al. (2012) Current understanding and management of nasopharyngeal carcinoma. Auris Nasus Larynx 39: 137-144. [Crossref]

12. Cheung CC, Chung GT, Lun SW, To KF, Choy KW, et al. (2014) miR-31 is consistently inactivated in EBV-associated nasopharyngeal carcinoma and contributes to its tumorigenesis. Mol Cancer 13:184. [Crossref]

13. Henle G, Henle W (1976) Epstein-Barr virus-specific IgA serum antibodies as an outstanding feature of nasopharyngeal carcinoma. Int J Cancer 17: 1-7. [Crossref]

14. Gulley ML, Tang W (2008) Laboratory assays for Epstein-Barr virus-related disease. $J$ Mol Diagn 10: 279-292. [Crossref]

15. Kim NR, Lin Z, Kim KR, Cho HY, Kim I (2005) Epstein-Barr virus and p16INK4A methylation in squamous cell carcinoma and precancerous lesions of the cervix uteri. $J$ Korean Med Sci 20: 636-642. [Crossref]

16. Dou H, Hu D, Lam C, Liu Y, Wang X, et al. (2014) Retrospective analysis of results of treatment for nasopharyngeal carcinoma in Macao. Chin J Cancer Res 26: 148-158. [Crossref]

Copyright: (C2016 AlDhahri S. This is an open-access article distributed under the terms of the Creative Commons Attribution License, which permits unrestricted use, distribution, and reproduction in any medium, provided the original author and source are credited. 